\title{
Meteotsunamis in Japan associated with the Tonga Eruption
}

\section{in January 2022}

\author{
Ryuho Kataoka ${ }^{1,2,3}$, Stephen D. Winn ${ }^{3,4}$, and Emile Touber ${ }^{3,4}$ \\ ${ }^{1}$ National Institute of Polar Research, Tachikawa, Japan \\ ${ }^{2}$ SOKENDAI, The Graduate University for Advanced Studies, Japan \\ ${ }^{3}$ Okinawa Institute of Science and Technology Graduate University, Japan \\ ${ }^{4}$ Department of Mechanical Engineering, Imperial College London
}

Corresponding author: Ryuho Kataoka, National Institute of Polar Research, 10-3 Midoricho, Tachikawa 190-8518, Japan. E-mail: kataoka.ryuho@nipr.ac.jp

This manuscript has been submitted for publication in Scientific Online Letters on the Atmosphere (SOLA). Please note that, despite having undergone peer-review, the manuscript has yet to be formally accepted for publication. Subsequent versions of this manuscript may have slightly different content. If accepted, the final version of this manuscript will be available via a link on this webpage. 


\begin{abstract}
Large-amplitude meteotsunamis were observed in many areas in Japan, following the arrival of barometric Lamb waves emitted by an underwater volcanic eruption of Hunga Tonga-Hunga Ha'apai in January 2022. We modeled the power spectra of the tidal level data obtained from 12 tide stations of the Geospatial Information Authority of Japan, based on a single transfer function which converts the barometric pressure pulse spectra into the meteotsunami spectra. The pressure pulse spectra are obtained from the ensemble average of $\sim 1500$ Soratena weather sensors of Weathernews Inc. distributed over Japan. The observed meteotsunami spectra can be characterized by the enhanced seiche eigenmodes at each station excited by the mesoscale pressure pulse, which contributes for accumulating the necessary knowledge to understand the potential dangers in various different areas over Japan.
\end{abstract}

\title{
1. Introduction
}

On January 15, 2022, at 0400 UT, an underwater volcanic eruption of Hunga TongaHunga Ha'apai at 20.54 S and $175.39 \mathrm{~W}$ produced a barometric pressure pulse, globally spreading out in concentric circles from the volcano (Figure 1, Supplement 1), circling the Earth for at least two days. The pressure pulse is called an atmospheric Lamb wave, which is generated by the expansion of the air around the volcano due to the heat of the eruption. Lamb waves travel at $\sim 310 \mathrm{~m} / \mathrm{s}$, slightly slower than the sound speed, and are characterized by weak attenuation over long distances (Nishida et al., 2014). 

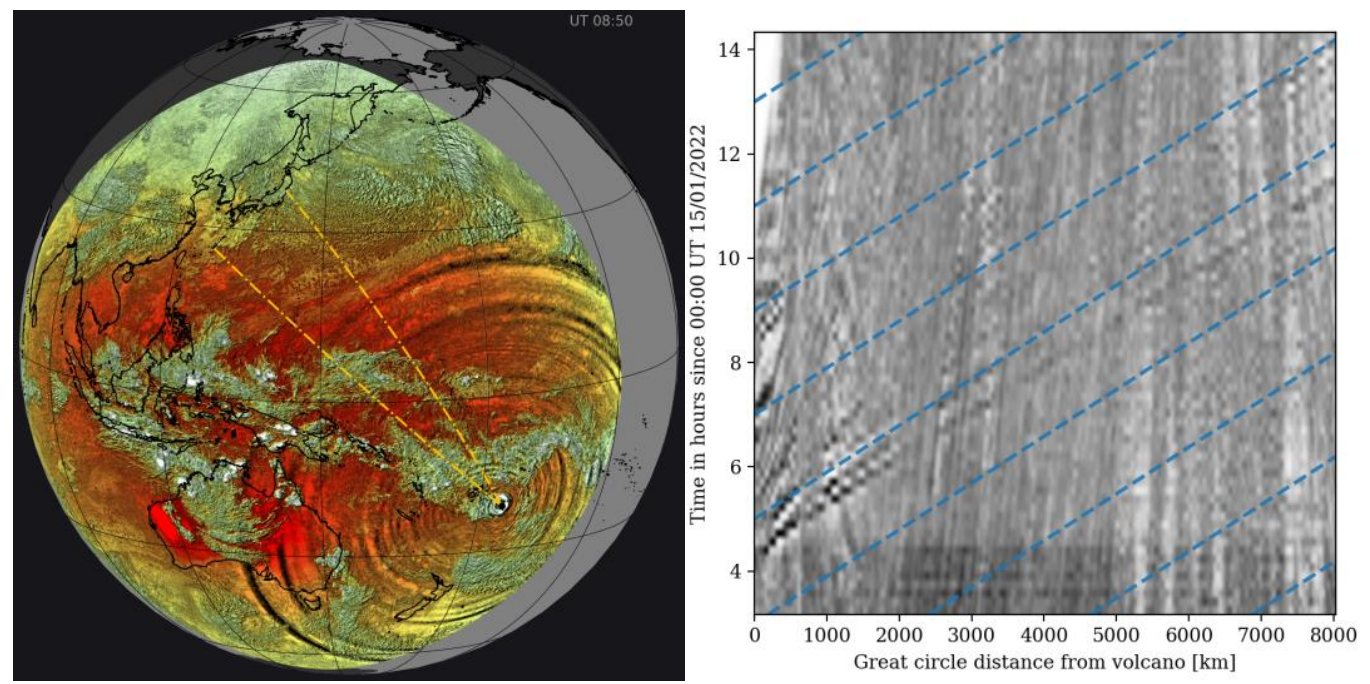

Figure 1: (a) The color and cloud shading are based on band 8 which is IR centered around 6.2um, the Lamb wave is shown using time-derivative estimates on band 10 which is IR centered around 9.7um, and smoothed using a Laplacian operator applied in longitude-latitude space. The orange dashed lines indicate the straight path from the volcano to the most extreme in latitude stations used in this study. See Supplement 1 (Movie A) for the movie. (b) Distance-time diagram for the Laplacianfiltered signal along the great circle path that joins the volcano and Okinawa, using Himawari-8 data. Diagonal dashed blue sloped lines of $v=310 \mathrm{~m} / \mathrm{s}$ for reference.

When the first wave front passed through Japan, a pressure pulse of $\sim 2 \mathrm{hPa}$ was observed at $\sim 1100$ UT (1900-2000 JST), and immediately after that, a large disturbance of the tidal level was observed over a wide area, especially along the Pacific coast of Japan, including the largest amplitude of $\sim 1.2 \mathrm{~m}$ at Amami station. This phenomenon is known as a meteorological tsunami or meteotsunami, and in Japan it has been known as the Abiki phenomenon, which is local and unique to Nagasaki Bay (Hibiya and Kajiura, 1982). A similar pressure pulse and meteotsunami have occurred in the past during the 
eruption of Krakatoa volcano in Indonesia in 1883 (Harkrider and Press, 1962).

The Japan Meteorological Agency (JMA), which had predicted in the evening that the Tonga eruption would have no impact in Japan, was surprised by the meteotsunami, which started a few hours earlier than the predicted arrival time of any possible tsunami. JMA then issued tsunami warnings in many areas at around midnight when the meteotsunami amplitude peaked. The warning lasted for more than a half day and was canceled at 2:00 p.m. JST. In order to mitigate the confusion and possible damage caused by similar phenomena in the future, an overview of the basic characteristics of the meteotsunamis observed in various parts of Japan would be useful.

Meteotsunamis are amplified due to the combination of atmospheric pressure and oceanic resonance at multiple stages, such as Proudman, shelf, and harbor effects (Proudman, 1929; Hibiya and Kajiura 1982; Monserrat et al., 2006). Among those known effects, we particularly focus on the local harbor resonance working at the last stage. As for the power spectrum analysis method, to reconstruct the transfer function for atmospherically generated seiches, we followed Monserrat et al. (1998).

The purpose of this study is to examine whether the power spectrum of meteotsunamis observed over a wide area of Japan can be roughly estimated from a single transfer function by inputting mesoscale power spectrum of atmospheric pressure pulse, based on the localized resonance spectrum of seiches specific to each region.

\section{Data and Method of Analysis}

We use the $30 \mathrm{~s}$ values of tidal level data published realtime by the Geospatial Information Authority of Japan (GSI). The tidal level resolution is mm. Twelve stations 
out of 25 GSI tide stations are facing the Pacific Ocean (Figure 2), and clearly respond to the pressure pulses.

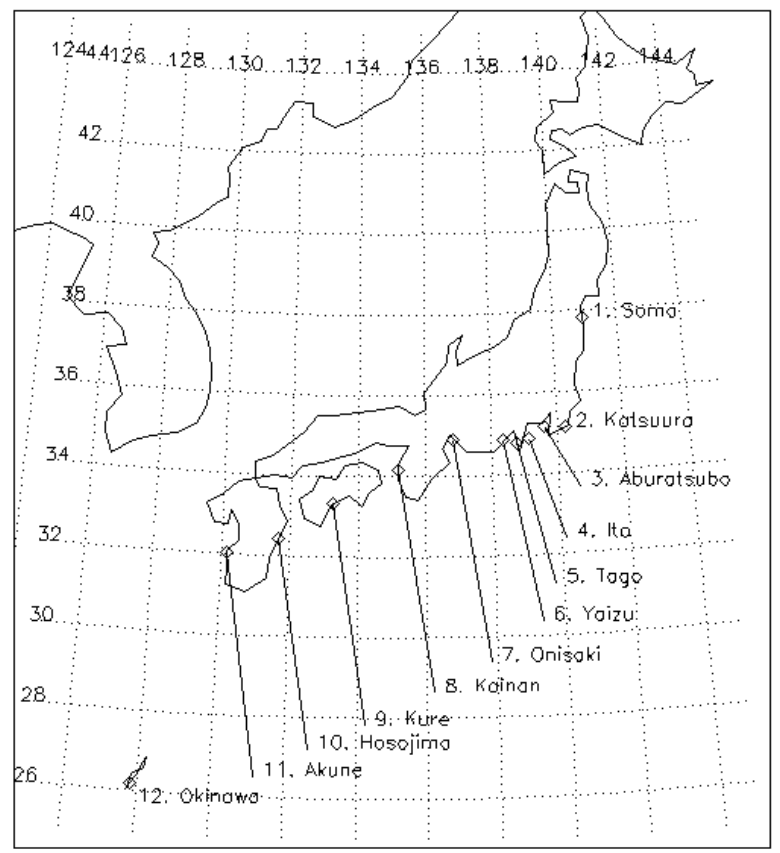

Figure 2: Map of 12 tide stations used in this study.

As a pre-processing step for spectral analysis, only the high-frequency components were extracted by subtracting the 60 min moving average values for all data. To estimate the background seiche spectrum $S_{b}$ at each location, the ensemble average was adopted for a total of 47 power spectra, which were shifted by 2 hours using a 4-hour window, using 4-day data preceding the event starting at 0000 UT on January 11, 2022. The meteotsunami power spectra $S_{o b s}$ were obtained for the 24-hour time periods; the first pressure pulse roughly occurred from $\sim 1100$ UT on Jan. 15, and the second pressure pulse occurred from $\sim 0000$ UT on January 17 . The second meteotsunami event is relatively weak, and an example from Okinawa station is shown in Figure 3. Some areas react more or less than others during that interval. 



Figure 3: Example of high-pass filtered time series of (top) tidal level and (bottom) barometric pressure from Okinawa. The red line is the explosion time, the grey lines are the pressure pulse timings and the blue line the tsunami arrival time. The grey coloring indicates the time during which the pulse should have arrived but not the tsunami.

Taking the great circle distance from the volcano to each of the tide monitoring stations, the arrival times from the explosion time are estimated for the first pressure pulse (p0, assuming $\mathrm{c}=310 \mathrm{~m} / \mathrm{s}$ ), the tsunami ( $\mathrm{h}$, based on the characteristic speed using the mean bathymetry along that great circle line), the inverse pressure pulse (p1) and a second passage of the pressure pulse (p2).

For the pressure pulse analysis, we also utilize the $1 \mathrm{~min}$ barometric pressure data of 
3000 SORATENA stations distributed over Japan, as provided by Weathernews Inc. The resolution is $0.1 \mathrm{hPa}$, and the example data is shown in Figure 4 For the pressure pulse time intervals, gapless data are available for $\sim 1500$ stations. As a pre-processing step for consistent spectral analysis, the barometric pressure data were linearly interpolated to double the number of data points, and only the high-frequency components were extracted by subtracting the 60 min moving average values.


Figure 4: Propagating pressure pulses for (a) the first wave at $t=10-14 h$, (b) inverse propagation wave at $\mathrm{t}=31-35 \mathrm{~h}$, and (c) the second returning wave at $\mathrm{t}=47-51 \mathrm{~h}$.

As shown in Figure 4, the propagating pressure pulses can be clearly visualized by the Soratena weather stations, taking the angular distance of each station from the Tonga eruption. The phase speed of the first Lamb wave is roughly estimated to be $310 \mathrm{~m} / \mathrm{s}$ with the dominant wavelength of 500-600 km, which gives the basic temporal variation at 15 20 min. More detailed analysis of the Lamb wave fronts is beyond the scope of this study. We applied our spectral analysis for the first and the returning pressure pulses (Figure 
4a and 4c) and omitted the inverse propagation event (Figure $4 \mathbf{b}$ ). The barometric pressure spectra $P$ are obtained for 4-hour time interval for the first and second events, and ensemble averaging was performed at gapless $\sim 1500$ locations (Figure 5a).

The transfer function $T$ converts from the pressure spectrum $P$ to the meteorological tsunami spectrum $\mathrm{S}_{\mathrm{obs}}$, which is obtained by the following equation:

$$
T(\omega)=\left(\frac{S_{o b s}(\omega)}{S_{b}(\omega)}-1\right) \frac{E_{b}(\omega)}{P(\omega)},
$$

where $S_{b}$ and $S_{o b s}$ are the power spectra of background seiche and the observed meteotsunami. $E_{b}$ is the background ocean spectrum, which is virtually universal (Kulikov et al., 1983) and can be described with a constant $A$ by $E_{b}(\omega)=A \omega^{-2}$. We estimate the single averaged transfer function $T_{\text {ave }}$ by averaging all of 24 transfer functions obtained from 12 stations for the first and second events. The averaged transfer function is shown in Figure 5, where $A$ is assumed to be $10^{-3} \mathrm{~cm}^{2} \mathrm{cpm}$ (Rabinovich, 1997). The model spectra are then obtained by the following equation:

$$
S_{\text {model }}(\omega)=S_{b}(\omega)+\frac{T_{a v e}(\omega) P(\omega) S_{b}(\omega)}{E_{b}(\omega)}
$$


(a)

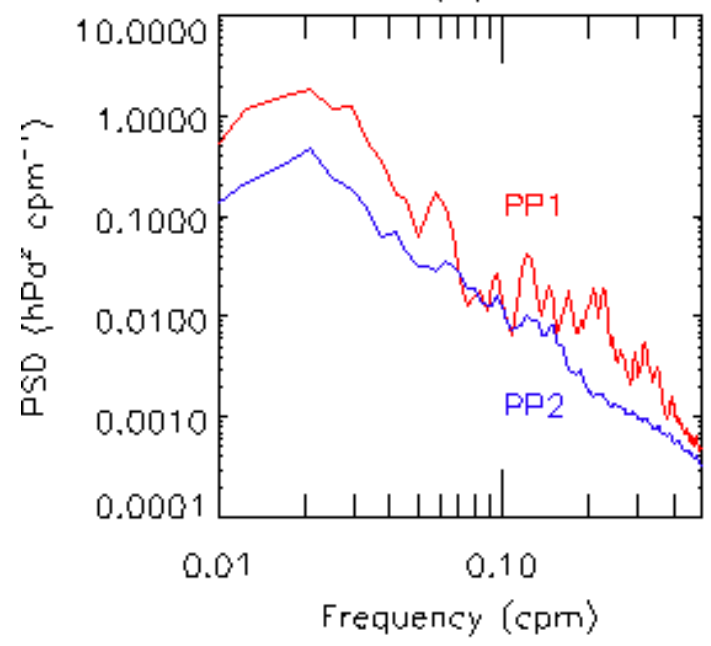

(b)

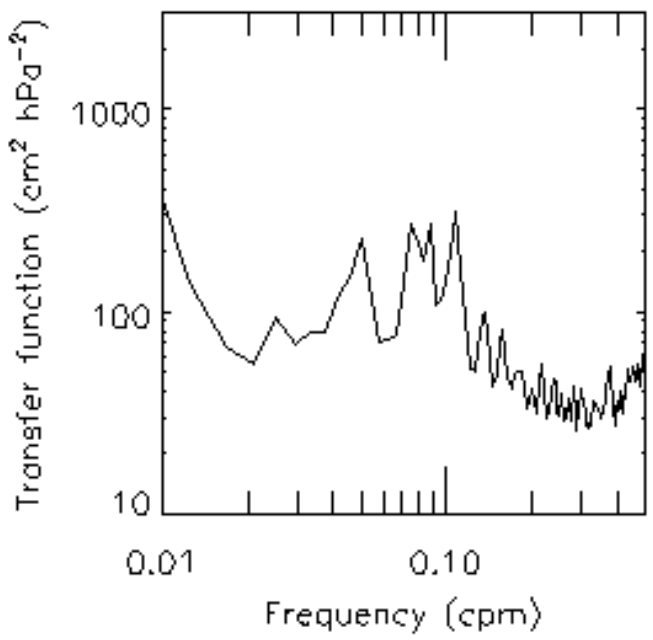

Figure 5: (a) Power spectral density of pressure pulse event 1 (red) and event 2 (blue); (b) averaged transfer function.

\section{Results}

The observed spectra, background spectra, and model spectra are shown for 12 stations, in Figures 6 and 7, for the first and second waves, respectively. At all stations, the seiche eigenmodes are clear with a few peaks appearing in the background spectra. Similar but amplified resonant features are evident in observed spectra and model spectra, suggesting the importance of "Abiki" for various different stations in Japan. 



Figure 6: Observed meteotsunami spectra (black), background seiche spectra (blue), and model spectra (red) of the first meteotsunami event for the 24-hour time interval from 1000 UT on January 15, 2022. 



Figure 7: Observed meteotsunami spectra (black), background seiche spectra (blue), and model spectra (red) of the second meteotsunami event for the 24-hour time interval from 2300 UT on January 16, 2022.

As shown in Figures 6 and 7, the observed and modeled spectra roughly show good agreement over a wide frequency range, although the model tends to overestimate the meteotsunami amplitude for the second event. The worst agreement is seen in Akune station (\#11), where the coast is differently facing parallel to the wave front (Figure 2). 


\section{Discussions}

First, the exact mechanisms of large amplification of the meteotsunami are still unclear, although the power spectra of tidal level can roughly be characterized by the transfer function. The deep sea around Japan has $8 \mathrm{~km}$ depth, and the speed of longwave phase speed is $\sim 280 \mathrm{~m} / \mathrm{s}$, which is close to the speed of the Lamb wave, so that Proudman resonance (Proudman, 1929) can play an important role. The standard wave steepening process at shelf by moving from deep water to shallow water can further amplify the event. The south-east facing direction of Japan coast was head-on direction to the wave front of pressure pulses (see Supplement 1: Movie A), which may also be a favorable condition to amplify the event to accept energetic inlet waves from open ocean. In this study, all of these effects are "absorbed" into the transfer function.

Second, we showed that the pressure spectra of $\mathrm{P}$ for only 4 hours gives a rough approximation of 24-hour meteotsunami trains. We interpret that this is also reasonable because the Proudman effect, with a different longwave phase speed and the Lamb wave speed, can continuously disturb the downstream ocean in similar frequency with the pressure pulse as they propagate, keeping disturbed inlets to shelf and harbor for a long time of more than a day, although the physics-based simulation study must follow to validate this speculation.

Third, we cannot fully ignore tsunami for this event. The expected arrival timings of tsunami to Japan Pacific coast are 1430-1530 UT (midnight of Japan) on January 15, 2022. The tidal waveform did not basically change as it looked like enhanced eigenmodes, but the amplitude of tide disturbance peaked around the expected tsunami arrival time at many stations, as also be seen in Figure 3, which may indicate the possible influence to amplify the first meteotsunami by the following tsunami disturbance. That may also 
explain the overestimation of the power spectra for second pressure pulse in which no later arrival of tsunami.

Finally, this study focused on Japan's local phenomena. However, to understand the ultimate cause and effects of meteotsunami events, and to obtain the real predictability by using physics-based time-domain forward model, it is essential to understand the global temporal and spatial evolution of the barometric pressure pulse itself that can drive meteotsunamis. The spatial structure of the Lamb waves changes according to the propagation from the eruption source and the interaction with the land and ocean. As shown in this study, since the barometric pressure pulse spectra as observed in each mesoscale region are the final necessary information for modeling and characterizing the local meteotsunami spectra, the properties of the overall Lamb and tsunami waves are an important output of future high-resolution simulation studies.

\section{Conclusions}

We examined the meteotsunami spectra for Tonga eruption event in January 2022. We highlighted the importance of localized resonance mechanism working at the last stage of multiple amplification steps, by showing the seiche eigenmodes are enhanced at each station associated with the pressure pulses. The observed meteotsunamis can be roughly characterized by a single transfer function, with the inputs of mesoscale pressure pulse spectra. 


\section{Acknowledgements}

The tidal level data was provided from GSI, barometric pressure data was provided by Weathernews Inc., and Himawari-8 images were provided by JMA.

\section{Supplements}

Supplement 1: Movie A. The color and cloud shading are based on band 8 which is IR centered around $6.2 \mathrm{um}$, the Lamb wave is shown using time-derivative estimates on band 10 which is IR centered around $9.7 \mathrm{um}$, and smoothed using a Laplacian operator applied in longitude-latitude space.

\section{References}

Harkrider D., and F. Press, 1967: The Krakatoa Air-Sea Waves: an Example of Pulse Propagation in Coupled Systems. Geophys. J. R. astr. Soc., 13, 149-159.

Hibiya, T., and K. Kajiura, 1982: Origin of the Abiki Phenomenon (a Kind of Seiche) in Nagasaki Bay. J. Oceanograph. Soc. Japan, 38, 172-182.

Kulikov, E. A., A. B. Rabinovich, A. I. Spirin, S. L. Poole, and S. L. Soloviev, 1983: Measurement of tsunamis in the open ocean. Mar. Geodesy, 6, 311-329.

Monserrat, S., A. B. Rabinovich, and B. Casas, 1998: On the reconstruction of the transfer function for atmospherically generated seiches. Geophys. Res. Lett., 25, $12,2197-2200$.

Monserrat, S., I. Vilibic, and A. B. Rabinovich, 2006: Meteotsunamis: atmospherically 
induced destructive ocean waves in the tsunami frequency band. Nat. Hazards Earth Syst. Sci., 6, 1035-1051.

Nishida, K., N. Kobayashi, and Y. Fukao, 2014: Background Lamb waves in the Earth's atmosphere. Geophys. J. Int. (2014) 196, 312-316 doi: 10.1093/gji/ggt413.

Proudman, J., 1929: The effects on the Sea of Changes in Atmospheric Pressure. Geophys. Suppl. Mon. Notices R. Astro. Soc., 2(4), 197-209.

Rabinovich, A. B., 1997: Spectral analysis of tsunami waves: Separation of source and topography effects. J. Geophys. Res., 102(C6), 12,663-12,676.

\section{List of Figure Captions}

Fig. 1. (a) The color and cloud shading are based on band 8 which is IR centered around 6.2um, the Lamb wave is shown using time-derivative estimates on band 10 which is IR centered around 9.7um, and smoothed using a Laplacian operator applied in longitude-latitude space. The orange dashed lines indicate the straight path from the volcano to the most extreme in latitude stations used in this study. See Supplement 1 (Movie A) for the movie. (b) Distance-time diagram for the Laplacian-filtered signal along the great circle path that joins the volcano and Okinawa, using Himawari-8 data. Diagonal dashed blue sloped lines of $\mathrm{v}=310 \mathrm{~m} / \mathrm{s}$ for reference.

Fig. 2. Map of 12 tide stations used in this study.

Fig. 3: Example of high-pass filtered time series of (top) tidal level and (bottom) barometric pressure from Okinawa. The red line is the explosion time, the grey lines are the pressure pulse timings and the blue line the tsunami arrival time. The grey coloring indicates the time during which the pulse should have arrived but not the 
tsunami.

Fig. 4: Propagating pressure pulses for (a) the first wave at $t=10-14 \mathrm{~h}$, (b) inverse propagation wave at $\mathrm{t}=31-35 \mathrm{~h}$, and (c) the second returning wave at $\mathrm{t}=47-51 \mathrm{~h}$.

Fig. 5: (a) Power spectral density of pressure pulse event 1 (red) and event 2 (blue); (b) averaged transfer function.

Fig. 6: Observed meteotsunami spectra (black), background seiche spectra (blue), and model spectra (red) of the first meteotsunami event for the 24 hour time interval from 1000 UT on January 15, 2022.

Fig. 7: Observed meteotsunami spectra (black), background seiche spectra (blue), and model spectra (red) of the second meteotsunami event for the 24 hour time interval from 2300 UT on January 16, 2022. 